\title{
28 Research Suare \\ Outcomes of Stereotactic Radiosurgery in Young Adults With Vestibular Schwannomas
}

\author{
Hirotaka Hasegawa \\ the University of Tokyo Hospital \\ Masahiro Shin \\ the University of Tokyo Hospital \\ Yuki Shinya \\ the University of Tokyo Hospital \\ Atsuto Katano \\ the University of Tokyo Hospital \\ Nobuhito Saito \\ the University of Tokyo Hospital
}

Mariko Kawashima ( $\square$ mariko.furi@gmail.com )

the University of Tokyo Hospital https://orcid.org/0000-0002-8337-5945

\section{Research Article}

Keywords: gamma knife, matched cohort analysis, stereotactic radiosurgery, vestibular schwannoma, younger patients

Posted Date: May 18th, 2021

DOI: https://doi.org/10.21203/rs.3.rs-526720/v1

License: (c) (1) This work is licensed under a Creative Commons Attribution 4.0 International License. Read Full License

Version of Record: A version of this preprint was published at Journal of Neuro-Oncology on July 9th, 2021. See the published version at https://doi.org/10.1007/s11060-021-03803-w. 


\section{Abstract}

Purpose: Vestibular schwannomas (VSs) are comparatively rare in younger patients, and stereotactic radiosurgery (SRS) outcome data are limited. We aimed to evaluate long-term SRS outcomes concerning sporadic VSs in patients aged $\leq 40$ years.

Methods: Of 383 patients with VS who had undergone SRS at our institution between 1990 and 2017, we compared younger and older patients' tumor control and radiation-induced complication rates using case-control propensity score (PS) matching.

Results: The mean follow-up was 83 and 92 months in older and younger patients, respectively. Compared with older patients, younger patients were more likely to have a history of resection $(20 \% \mathrm{vs}$. $39 \%, p=0.006$ ) and be treated with higher marginal doses (median, 12 Gy vs. 14 Gy; $p=0.014$ ). Cumulative 5- and 10-year tumor control rates were higher in older patients $(97.7 \%$ and $93.9 \%$, respectively) than in younger patients $(90.2 \%$ and $85.4 \%$, respectively, $p=0.024)$. After PS matching, younger patients' cumulative tumor control rates $(93.6 \%, 85.4 \%$, and $85.4 \%$ at 5,10 , and 15 years, respectively) were similar to those of older patients $(p=0.411)$. No significant between-cohort differences in hearing preservation rates or facial and trigeminal nerve complications were observed. Two younger patients had malignant tumors several years post-SRS, with one patient having confirmed histological transformation.

Conclusions: SRS is equally effective for younger and older patients. Complications other than hearing deterioration are uncommon. Malignant transformation is possible and long-term post-SRS surveillance MRI is important. These data are useful for decision-making involving young adults with VSs.

\section{Introduction}

Stereotactic radiosurgery (SRS) for small- to medium-sized vestibular schwannomas (VSs) is a safe and effective treatment [1-5]. VSs typically occur in middle-aged individuals [6], and occasionally in younger patients. It has been proposed that VSs in younger patients could have different biological features, such as a larger tumor size, high vascularity, and rapid growth [7-9], and attention to treatment outcomes in this age group is needed. However, to date, there is a paucity of data regarding SRS outcomes in younger patients.

Generally, clinicians hesitate to select SRS for younger patients with VS, as it is a benign tumor. Moreover, younger patients tend to have a longer life expectancy than do their older counterparts; differences between treatment modalities could be amplified over time. While several studies have reported long-term SRS outcomes across several age groups, such data are limited in younger patients. Furthermore, when compared with older patients, younger patients are less likely to have comorbidities associated with increased surgical risk and thus are more likely to be considered good candidates for resection. However, physicians need to consider that the decision-making process for younger patients can be more complicated and may differ from that for older patients. While surgical outcomes have improved 
significantly due to advances in microsurgery and electrophysiological monitoring techniques [10], the surgical burden remains high for patients, including inability to work for a significant period. Moreover, several studies have reported slightly better facial outcomes using SRS, which is less likely to cause temporary weakness $[2,3,5,11-14]$. In clinical practice, many younger patients with VS select SRS as a minimally invasive therapeutic modality. In addition, since younger patients have an increased risk of recurrence due to their longer follow-up periods, detailed outcomes of SRS as a salvage treatment for recurrence in this age group would be informative. This study aimed to compare long-term SRS outcomes concerning VSs between younger and older patients to provide useful information for treatment decisionmaking.

\section{Methods And Materials}

At our institution, 439 patients with VS had undergone SRS treatment, using a Leksell Gamma Knife (Elekta AB, Stockholm, Sweden) between 1990 and 2017. We excluded patients with neurofibromatosis type $2(n=23)$ and those without radiological follow-up data $(n=33)$; we included 383 patients in this study. There was no case of secondary SRS; a history of resection was correctly identified. We defined "younger" patients as those aged $\leq 40$ years and "older" patients as those aged $>40$ years.

This study was approved by the Institutional Review Board (IRB number 2231), and all participants provided written informed consent for the retrospective usage of their information.

\section{Radiosurgical techniques and post-treatment follow-up}

After head fixation using a Leksell Coordinate Frame G (Elekta Instruments, Stockholm, Sweden), stereotactic imaging by computed tomography or/and magnetic resonance imaging (MRI) was performed. Radiosurgical plans were created using commercially available planning software (KULA until 1998, Leksell Gamma Plan®, Elekta Instruments). During the 1990s, a marginal dose of 14-18 Gy was used for most patients. As lower-dose radiosurgery has been associated with a lower risk of radiationinduced complications, a marginal dose of $12 \mathrm{~Gy}$ has been uniformly selected since 2000 [15-16].

Routine post-treatment radiological follow-up comprised 6-monthly MRIs for the first 3 years and every year thereafter. Successful tumor control was defined as the lack of requirement for additional interventions to treat VSs, including microsurgical resection or secondary SRS. Progression and regression were defined as an increase and a decrease of $2 \mathrm{~mm}$ in any direction, respectively [4]. Transient tumor expansion was carefully determined by neurosurgeons and radiologists. Although typically occurring at approximately 6 months post-SRS and followed by shrinkage at approximately 18 months [17], if tumor increase was followed by spontaneous regression more than 2 years post-SRS, it was also considered transient expansion. A tumor was defined as cystic when the cyst diameter exceeded $50 \%$ of the maximum axial tumor diameter in the cerebellopontine angle [18]. Patients who retained a pure tone average (PTA) of $\leq 50 \mathrm{~dB}$ for the ear ipsilateral to the tumor were regarded as having preserved hearing function, instead of having a full evaluation using both PTA and speech discrimination 
scores because of limited speech discrimination score data. The pre-SRS hearing level was divided into categories of $\leq 30 \mathrm{~dB}$ and $31-50 \mathrm{~dB}$. Cranial nerve complications were defined as newly developed cranial nerve deficits or worsening of existing deficits that were either temporary or permanent. Diseaseassociated comorbidities and delayed adverse events were equally identified. These data were prospectively collected by the attending physicians.

\section{Statistical analysis}

Patient baseline characteristics and radiosurgical dosimetry were summarized and compared between the cohorts using Fisher's exact test for categorical variables and the Mann-Whitney U-test for continuous variables. Continuous variables were dichotomized using their median values. Tumor control rates, as well as facial and trigeminal nerve deficit-free rates, were then calculated using the KaplanMeier method and were compared between the cohorts using the log-rank test. Factors potentially affecting tumor control and cranial nerve deficit-free rates were evaluated using the Cox proportional hazards model for bivariate and multivariate analyses. Along with age, other factors entered into the multivariate model were carefully selected based on previous studies.

Regarding hearing function, crude preservation rates were calculated and compared between the cohorts using Fisher's exact test. Factors associated with the preservation rates of PTA of $\leq 50 \mathrm{~dB}$ were examined, using logistic regression analysis. The characteristics of patients requiring ventriculoperitoneal shunting for communicating hydrocephalus were also evaluated, using logistic regression analysis.

We performed propensity score (PS) matching, as the small number of included younger patients could have biased the results. PS scores were generated, using a binary logistic regression model with the following five variables: sex, history of resection, rate of cystic tumor, tumor volume, and marginal dose. Thereafter, one-to-one matching, without any replacement, was completed using the nearest neighbor match with a caliper of 0.03 . Tumor control and cranial nerve deficit-free rates were also analyzed using these matched cohorts.

Statistical significance was set at $p$ values of $<0.05$. All analyses were performed using JMP Pro 15 software (SAS Institute, Cary, NC, USA).

\section{Results}

Baseline characteristics and radiosurgical parameters are summarized in Table 1. Younger study patients were aged $>20$ years, except for one teenager. Compared with older patients, younger patients were more likely to have a history of resection ( $20 \%$ vs. $39 \% ; p=0.006)$ and to have been treated with higher marginal doses (median, 12 Gy vs. $14 \mathrm{~Gy} ; \mathrm{p}=0.014$ ). No significant differences were observed between patients in either cohort on other factors. 
Table 1

Baseline characteristics and radiosurgical parameters

\begin{tabular}{|lllll|}
\hline Variables & Entire cohort & Older & Younger & p value \\
& $\mathbf{N}=\mathbf{3 8 3}$ & $\mathbf{N = 3 3 4}$ & $\mathbf{N}=49$ & \\
\hline Median age at SRS (range), year & $57(14-93)$ & $59(41-93)$ & $34(14-40)$ & $<0.001^{*}$ \\
\hline Male sex [\%] & $191[50]$ & $165[49]$ & $26[53]$ & 0.650 \\
\hline History of resection prior to SRS [\%] & $86[22]$ & $67[20]$ & $19[39]$ & $0.006^{*}$ \\
\hline Cystic tumor [\%] & $38[16]$ & $64[19]$ & $5[10]$ & 0.163 \\
\hline Median follow-up period (range), month & $84(4-345)$ & $83(4-345)$ & $92(7-340)$ & 0.250 \\
\hline Median tumor volume (range), mL & $1.4(0.1-$ & $1.3(0.1-$ & $1.5(0.1-$ & 0.534 \\
\hline Median maximum diameter (range), & $16.7)$ & $16.7)$ & $6.8)$ & \\
\hline mm & $18(0.8-37)$ & $18(0.8-37)$ & $18.2(4-26)$ & 0.418 \\
\hline Median marginal dose (range), Gy & $12(8-25.2)$ & $12(8-25.2)$ & $14(12-20)$ & $0.014^{*}$ \\
\hline Median maximum dose (range), Gy & $26.7(16-$ & $27(16-40)$ & $28(17-36)$ & 0.856 \\
\hline
\end{tabular}

${ }^{*} p$ values $<0.05$ are considered statistically significant.

SRS, stereotactic radiosurgery

Matched cohorts included 44 patients per age group. After matching, there were no significant betweencohort differences in baseline characteristics, except for age (Table 2). Standardized differences that were of $<0.2$ suggested adequate variable balance after matching. 
Table 2

Baseline characteristics and radiosurgical parameters after matching

\begin{tabular}{|lllll|}
\hline Variables & $\begin{array}{l}\text { Older } \\
\mathbf{N}=\mathbf{4 4}\end{array}$ & $\begin{array}{l}\text { Younger } \\
\mathbf{N}=\mathbf{4 4}\end{array}$ & $\begin{array}{l}\mathbf{p} \\
\text { value }\end{array}$ & $\begin{array}{l}\text { Standard } \\
\text { difference }\end{array}$ \\
\hline Male sex [\%] & $22[50]$ & $23[52]$ & 1.000 & 0.05 \\
\hline History of resection prior to SRS [\%] & $14[32]$ & $15[34]$ & 1.000 & 0.05 \\
\hline Cystic tumor [\%] & $4[9]$ & $5[11]$ & 1.000 & 0.07 \\
\hline $\begin{array}{l}\text { Median follow-up period (range), } \\
\text { month }\end{array}$ & $94(8-338)$ & $\begin{array}{l}90.5(7- \\
340)\end{array}$ & 0.930 & 0.01 \\
\hline Median tumor volume (range), mL & $1.5(0.1-8.6)$ & $\begin{array}{l}1.5(0.01- \\
6.8)\end{array}$ & 0.845 & 0.01 \\
\hline $\begin{array}{l}\text { Median maximum diameter (range), } \\
\text { mm }\end{array}$ & $18(7-32)$ & $18(4-26)$ & 0.864 & 0.05 \\
\hline Median marginal dose (range), Gy & $\begin{array}{l}12.3(12- \\
18.2)\end{array}$ & $\begin{array}{l}12(12- \\
20.4)\end{array}$ & 0.646 & 0.03 \\
\hline Median maximum dose (range), Gy & $28(21.5-$ & $24(17-36)$ & 0.334 & 0.15 \\
\hline
\end{tabular}

Standardized differences $<0.20$ are considered an adequate balance.

SRS, stereotactic radiosurgery

\section{Tumor control rate}

Tumor regression was confirmed in 237 (62\%), stable tumors in $118(31 \%)$, and enlargement in $28(7 \%)$ patients. Fifteen patients underwent a secondary treatment for tumor enlargement with or without neurological deterioration at the median of 40 months after SRS; of these, 14 patients underwent resection, and one patient underwent secondary SRS. None of the patients required salvage treatment 10 years after SRS.

The cumulative tumor control rates were $97.0 \%, 94.5 \%$, and $94.5 \%$ at 5,10 , and 15 years, respectively. The cumulative 5- and 10-year tumor control rates in the older cohort were $97.7 \%$ and $93.9 \%$, respectively, and those in the younger cohort were $90.2 \%$ and $85.4 \%$, respectively. These rates were significantly higher in the older than in the younger cohort $(p=0.024 ;$ Fig. $1 \mathrm{~A})$. In the younger cohort, the 5 - and 10 -year cumulative tumor control rates were $91.5 \%$ and $81.5 \%$, respectively, following SRS as a primary treatment, and $100 \%$ and $90 \%$ following SRS as a salvage after an initial surgery. Although the rates appeared better when SRS was used as a primary treatment than otherwise, there was no significant difference between the survival curves $(p=0.532$; Fig. 1B). Cox proportional hazard analyses showed the following factors were not significantly associated with tumor control: maximum tumor diameter $(p=0.495)$, tumor volume 
$(p=0.906)$, cystic tumor $(p=0.999)$, and marginal dose $(p=0.328)$. Younger age was significantly associated with a lower tumor control rate in univariate analysis (hazard ratio [HR] 3.21, 95\% confidence interval [Cl] 1.10-9.40; $p=0.033)$. However, in multivariate analysis, younger age was not statistically significant when adjusted for tumor volume, cystic tumor, and marginal dose (Table 3 ). In the PS matched cohort, tumor control rates were as follows: older cohort, $97.7 \%, 93.9 \%$, and $93.9 \%$ at 5,10 , and 15 years; younger cohort, $93.6 \%, 85.4 \%$, and $85.4 \%$ at 5,10 , and 15 years, respectively. The log-rank test showed that tumor control rates did not differ significantly between the cohorts $(p=0.411$; Fig. $1 C)$.

Table 3

Factors associated with tumor control rates

\begin{tabular}{|lllll|}
\hline Variables & \multicolumn{3}{l}{ Bivariate } & \multicolumn{2}{l|}{ Multivariate } \\
\cline { 2 - 5 } & p value & Hazard ratio & p value & Hazard ratio \\
& & {$[95 \%$ Cl] } & & [95\% Cl] \\
\hline Age (continuous) & 0.324 & $0.22[0.01-4.90]$ & $/$ & $/$ \\
\hline Age, $\leq 57$ years & 0.622 & $1.30[0.46-3.65]$ & $/$ & $/$ \\
\hline Age, $\leq 40$ years & $0.033^{*}$ & $3.21[1.10-9.40]$ & 0.072 & $2.76[0.91-8.35]$ \\
\hline Male sex & 0.078 & $0.36[0.11-1.12]$ & $/$ & $/$ \\
\hline Maximum diameter, $>18 \mathrm{~mm}$ & 0.991 & $1.00[0.36-2.83]$ & $/$ & $/$ \\
\hline $\begin{array}{l}\text { Maximum diameter } \\
\text { (continuous) }\end{array}$ & 0.495 & $3.12[0.11-74.3]$ & $/$ & $/$ \\
\hline Tumor volume, $>1.5$ mL & 0.671 & $1.25[0.45-3.44]$ & 0.799 & $1.14[0.41-3.19]$ \\
\hline Tumor volume (continuous) & 0.906 & $1.27[0.01-27.3]$ & $/$ & $/$ \\
\hline Marginal dose (continuous) & 0.328 & $\begin{array}{l}5.11[0.12- \\
91.55]\end{array}$ & 0.465 & $3.51[0.07-$ \\
\hline Cystic tumor & 0.989 & $0.02[0.10-$ & $/$ & $/$ \\
\hline History of resection & 0.224 & $1.95[0.67-5.70]$ & 0.398 & $1.61[0.53-4.88]$ \\
\hline
\end{tabular}

${ }^{*} p$ values $<0.05$ are considered statistically significant.

$\mathrm{Cl}$, confidence interval

\section{Facial and trigeminal nerve function preservation}

Among the entire cohort, any facial nerve deficits were observed in $52(13.6 \%)$ patients at the median of 7 months (range 0.1-227 months); trigeminal nerve deficits were identified in 39 (10\%) patients. The 1- and 5-year cumulative rates of being free from facial and trigeminal nerve deficits were $89.4 \%, 86.2 \%$, and 
$91.0 \%, 90.4 \%$, respectively. The log-rank tests showed no significant difference between the cohorts (both before and after matching) in the cumulative rates of being free from any facial and trigeminal nerve deficits. According to multivariate Cox proportional hazards analysis, a higher marginal dose (continuous) was a risk factor for facial nerve deficits (HR 296.9, 95\% Cl 42.2-1843.9; $\mathrm{p}<0.001$ ). A higher marginal dose (HR 97.60, 95\% Cl 10.18-935.92; p < 0.001) and history of resection (HR $2.12,95 \% \mathrm{Cl}$ $1.06-4.24 ; p=0.033$ ) were risk factors for trigeminal nerve deficit.

\section{Hearing preservation}

Details concerning the number of patients who retained the PTA of $\leq 50 \mathrm{~dB}$ at SRS and at final follow-up are summarized in Table 4. At baseline, the younger cohort had slightly more patients with the PTA of $\leq$ $30 \mathrm{~dB}$ than did the older cohort (39\% vs. $21 \%$; $p=0.028)$. Among $161(42 \%)$ patients with the PTA of $\leq 50$ dB at SRS, 69 (43\%) patients had retained same hearing level at final follow-up. There was no significant difference between the younger and older cohorts $(44 \%$ vs. $43 \% ; p=1.000)$. Multivariate analysis showed that only PTA of $\leq 30 \mathrm{~dB}$ at SRS predicted serviceable hearing at the final follow-up (HR $3.90,95 \% \mathrm{Cl}$ $1.95-7.80 ; p<0.001)$, whereas none of the other factors including tumor volume $(>1.5 \mathrm{~mL}, p=0.990)$, marginal dose $(>12 \mathrm{~Gy}, \mathrm{p}=0.140)$, and younger age $(p=0.842)$ predicted serviceable hearing.

Table 4

Crude preservation rates in patients with PTA $\leq 50 \mathrm{~dB}$ at SRS.

\begin{tabular}{|c|c|c|c|c|c|c|}
\hline & \multicolumn{3}{|c|}{ Older $(\mathrm{N}=334)$} & \multicolumn{3}{|c|}{ Younger $(\mathrm{N}=49)$} \\
\hline & $\begin{array}{l}\text { PTA } \leq 30 \\
\text { dB at SRS }\end{array}$ & $\begin{array}{l}\text { PTA }>30 \\
\text { dB at SRS }\end{array}$ & total & $\begin{array}{l}\text { PTA } \leq 30 \\
\mathrm{~dB} \text { at SRS }\end{array}$ & $\begin{array}{l}\text { PTA }>30 \\
\mathrm{~dB} \text { at SRS }\end{array}$ & total \\
\hline $\begin{array}{l}\text { Serviceable hearing at } \\
\text { SRS, patients [\%] }\end{array}$ & 69 & 67 & $\begin{array}{l}136 \\
{[41]}\end{array}$ & 19 & 6 & $\begin{array}{l}25 \\
{[51]}\end{array}$ \\
\hline $\begin{array}{l}\text { Serviceable hearing at last } \\
\text { follow-up, patients }\end{array}$ & 41 & 17 & 58 & 9 & 2 & 11 \\
\hline $\begin{array}{l}\text { Hearing preservation rates, } \\
\%\end{array}$ & $59 \%$ & $25 \%$ & $43 \%$ & $47 \%$ & $17 \%$ & $44 \%$ \\
\hline
\end{tabular}

PTA, pure-tone audiometry; SRS, stereotactic radiosurgery

\section{Other adverse events}

In the entire cohort, 12 patients required ventriculo-peritoneal shunting due to hydrocephalus, at the median of 11.5 (range, 1-29) months after SRS. No risk factor was associated with the shunting procedure, including the age of $>40$ years and tumor volume of $>1.5 \mathrm{~mL}$. Late adverse reaction to radiation, specifically, cyst formation was observed in six patients (median, 59 months post-SRS). One patient underwent resection of the cyst due to progressive trigeminal nerve deficit, while the others had stable disease without need for surgery. Second, three older patients ( $>50$ years old at SRS) developed an anterior-inferior cerebellar aneurysm in the irradiated field. While one patient had a subarachnoid hemorrhage, two patients were adequately treated prior to aneurysmal rupture [19]. No aneurysmal 
formation was observed in the younger cohort. Finally, we identified two patients in the younger cohort (age at SRS, 26 and 35 years, respectively) who developed malignant peripheral nerve sheath tumors after SRS. Of these two patients, one had surgical specimens taken pre- and post-SRS demonstrating malignant transformation [20]. The other patient underwent primary SRS, without pathological examination pre-SRS. Given the pre-SRS rapid tumor growth observed in this patient, it was unclear whether malignant transformation had occurred or whether the tumor was originally malignant. No statistically significant between-cohort difference in the rate of delayed adverse radiation events was found.

\section{Discussion}

In this study, we compared SRS outcomes for VSs between younger and older patients. No significant between-cohort differences were found in the tumor control rate based on multivariate analysis or through comparisons using PS matching. There were no significant between-cohort differences in the incidence of facial and trigeminal nerve deficits after SRS. The crude hearing preservation rate was $44 \%$ in the younger cohort, which was similar to that in the older cohort.

Regarding surgical resection for VS, Sughrue et al. evaluated outcomes in 208 patients aged $<40$ years (median follow-up, 10.2 years) [21]. Surgical resection led to durable long-term freedom from tumor recurrence or progression in $89 \%$ of patients at 15 years follow-up. However, studies concerning SRS in younger patients with VS are scarce. Most studies that included patients of all ages have not confirmed whether age could influence tumor control; although age groups varied, few studies have focused on outcomes in young adults. In 2009 , one study reported that the tumor control rate in patients aged $\leq 40$ years was $96 \%$ at 5 years and that the incidence of cranial nerve deficits was extremely rare at the median follow-up period of 5.3 years [22]. Through comparisons with an older cohort using PS matching, our study results indicated that SRS was equally effective for younger patients. Moreover, our longer follow-up period provided additional supportive evidence of long-term durability.

Careful consideration is required when managing patients following SRS. It can be challenging to differentiate between true tumor progression and pseudo-progression, in particular, for younger patients, where the threshold of salvage surgery may be lowered, as additional resections are generally tolerable in this age group. Recent studies, in contrast to conventional wisdom, have shown that transient expansion may occur later than 2 years post-SRS and the growth rate may occasionally exceed $50 \%$ in volume increase [23-25]. Thus, tumors not causing disturbing symptoms or brainstem compression may be amenable to observation despite a certain rate of progression. Close discussion with skull-base surgeons is likely to enhance the decision-making process.

Previous studies have reported possible advantages in younger patients after SRS, for example, a reduced risk of hydrocephalus and balance disturbance [26]. This could not be determined in our study because of the small number of patients who underwent a shunting procedure in our cohort. Some controversy exists in terms of age effects on hearing preservation. Consistent with previous studies [27, 
28], the present study suggests that younger age may be non-advantageous for hearing preservation. This finding may be partly due to the present study eligibility criteria, which included patients with a shorter observation period. It may also imply that maintaining long-term hearing function remains challenging due to various risk factors intrinsic to VS [29], namely, the influence of irradiation and ischemic, mechanical, or chemical damage to the cochlear nerve due to VS itself [29,30]. However, advantages of younger age concerning hearing preservation have also been reported [31]. The Pittsburgh Hearing Prediction Score has been proposed as a method to predict long-term hearing outcomes prior to primary SRS [32]. In this scoring system, younger age, smaller tumor, and better hearing function prior to SRS have been shown to predict hearing preservation. Therefore, SRS for the selected patients with favorable hearing function remains promising as a first option; this recommendation should be verified in future clinical trials.

Delayed adverse radiation events are rare but problematic. Regarding aneurysm formation in the irradiated field, only 11 cases have been reported to date, one of which was a case we previously reported $[25,33-38]$. All the aneurysms were reported to be pseudoaneurysms and prone to rupture. The pathogenesis is unknown; however, given that most of the reported patients were aged $>40$ years at SRS, aging-related factors such as atherosclerosis may play a role alongside irradiation. Another significant concern is malignant transformation, which has been reported in more than 10 studies to date. However, only nine true radiation-induced malignancies have fulfilled Cahan's criteria [39], namely, cases showing histopathological evidence of transformation [20,40-46]. Neurofibromatosis type 2-related VS was the only possible risk factor and, based on systematic review findings, the incidence of malignant transformation is approximately $0.016 \%$ in sporadic VS cases following SRS with a latency period of up to 10 years [47]. Therefore, SRS should not be excluded as a therapeutic option for younger patients, provided long-term surveillance with MRI is feasible after SRS.

This study had several limitations. First, this study included a small sample of young adults. We included patients who underwent primary SRS and those who underwent salvage SRS after resection, possibly for relatively aggressive tumors. Although the variable of salvage SRS was adjusted after PS matching, a future study with only young patients without any intervention would be helpful. Second, hearing evaluation was not comprehensive due to the lack of speech discrimination score data. This could have influenced the hearing outcome, along with a relatively higher marginal dose in the younger cohort. Finally, even though we focused on younger patients, the younger cohort mainly comprised patients in their 30s; thus, this study did not sufficiently address outcomes in even younger patients. In theory, VSs in pediatric or very young patients could have different biological characteristics or might not be distinguishable from neurofibromatosis type 2; thus, more careful consideration is required [48]. Despite these limitations, this study contributes to the body of knowledge and is likely to be useful for decisionmaking regarding SRS for young adults with VS.

\section{Conclusion}


SRS can provide long-term sufficient tumor control for younger patients with an acceptable safety profile. Given concerns regarding late adverse radiation events, these patients should be monitored indefinitely, at least as a current recommendation. SRS is a reasonable therapeutic option for both younger and older patients, unless those patients have large tumors, compelling neurological symptoms, or pose challenges for long-term image surveillance. Our data are likely to facilitate a more informed decision-making process when counseling young adult patients with VS who require intervention.

\section{Declarations}

\section{Availability of data and materials}

The data supporting the findings of this study are included in the article and its supplementary material file.

\section{Compliance and ethical standards}

Conflicts of interest: The authors report no conflicts of interest.

Author Contributions: MK and HH conceived and designed the study. MK conducted the literature search. $\mathrm{MK}, \mathrm{HH}, \mathrm{YK}, \mathrm{AK}, \mathrm{MS}$ and NS were involved in the analysis and interpretation of data. MK and $\mathrm{HH}$ drafted the manuscript. The study was supervised by MS and NS. All authors read and approved the final manuscript.

\section{References}

1. Lunsford LD, Niranjan A, Flickinger JC, Maitz A, Kondziolka D (2005) Radiosurgery of vestibular schwannomas: summary of experience in 829 cases. J Neurosurg 102 Suppl:195-199

2. Pollock BE, Driscoll CL, Foote RL, Link MJ, Gorman DA, Bauch CD, Mandrekar JN, Krecke KN, Johnson $\mathrm{CH}$ (2006) Patient outcomes after vestibular schwannoma management: a prospective comparison of microsurgical resection and stereotactic radiosurgery. Neurosurgery 59:77-85; discussion 77-85. doi:10.1227/01.NEU.0000219217.14930.14

3. Boari N, Bailo M, Gagliardi F, Franzin A, Gemma M, del Vecchio A, Bolognesi A, Picozzi P, Mortini P (2014) Gamma knife radiosurgery for vestibular schwannoma: clinical results at long-term follow-up in a series of 379 patients. J Neurosurg 121 Suppl:123-142. doi:10.3171/2014.8.GKS141506

4. Klijn S, Verheul JB, Beute GN, Leenstra S, Mulder JJ, Kunst HP, Hanssens PE (2016) Gamma knife radiosurgery for vestibular schwannomas: evaluation of tumor control and its predictors in a large patient cohort in The Netherlands. J Neurosurg 124:1619-1626. doi:10.3171/2015.4.JNS142415

5. Hasegawa T, Kato T, Naito T, Tanei T, Ishii K, Tsukamoto E, Okada K (2020) Long-term outcomes of sporadic vestibular schwannomas treated with recent stereotactic radiosurgery techniques. Int $J$ Radiat Oncol Biol Phys 108:725-733. doi:10.1016/j.ijrobp.2020.05.029 
6. Babu R, Sharma R, Bagley JH, Hatef J, Friedman AH, Adamson C (2013) Vestibular schwannomas in the modern era: epidemiology, treatment trends, and disparities in management. J Neurosurg 119:121-130. doi:10.3171/2013.1.JNS121370

7. Allcutt DA, Hoffman HJ, Isla A, Becker LE, Humphreys RP (1991) Acoustic schwannomas in children. Neurosurgery 29:14-18. doi:10.1097/00006123-199107000-00003

8. Harada K, Nishizaki T, Adachi N, Suzuki M, Ito H (2000) Pediatric acoustic schwannoma showing rapid regrowth with high proliferative activity. Childs Nerv Syst 16:134-137. doi:10.1007/s003810050479

9. Pothula VB, Lesser T, Mallucci C, May P, Foy P (2001) Vestibular schwannomas in children. Otol Neurotol 22:903-907. doi:10.1097/00129492-200111000-00032

10. Rinaldi V, Casale M, Bressi F, Potena M, Vesperini E, De Franco A, Silvestri S, Zini C, Salvinelli F (2012) Facial nerve outcome after vestibular schwannoma surgery: our experience. J Neurol Surg B Skull Base 73:21-27. doi:10.1055/s-0032-1304559

11. Falcioni M, Fois $P$, Taibah A, Sanna M (2011) Facial nerve function after vestibular schwannoma surgery. J Neurosurg 115:820-826. doi:10.3171/2011.5.JNS101597

12. Ansari SF, Terry C, Cohen-Gadol AA (2012) Surgery for vestibular schwannomas: a systematic review of complications by approach. Neurosurg Focus 33:E14. doi:10.3171/2012.6.FOCUS12163

13. Bloch O, Sughrue ME, Kaur R, Kane AJ, Rutkowski MJ, Kaur G, Yang I, Pitts LH, Parsa AT (2011) Factors associated with preservation of facial nerve function after surgical resection of vestibular schwannoma. J Neuro-Oncol 102:281-286. doi:10.1007/s11060-010-0315-5

14. Johnson S, Kano H, Faramand A, Pease M, Nakamura A, Hassib M, Spencer D, Sisterson N, Faraji AH, Arai Y, Monaco E, Niranjan A, Flickinger JC, Lunsford LD (2019) Long-term results of primary radiosurgery for vestibular schwannomas. J Neuro-Oncol 145:247-255. doi:10.1007/s11060-01903290-0

15. Flickinger JC, Kondziolka D, Niranjan A, Lunsford LD (2001) Results of acoustic neuroma radiosurgery: an analysis of 5 years' experience using current methods. J Neurosurg 94:1-6. doi:10.3171/jns.2001.94.1.0001

16. Niranjan A, Lunsford LD, Flickinger JC, Maitz A, Kondziolka D (1999) Dose reduction improves hearing preservation rates after intracanalicular acoustic tumor radiosurgery. Neurosurgery 45:753762. doi:10.1097/00006123-199910000-00003 discussion 762 - 755.

17. Mindermann T, Schlegel I (2014) How to distinguish tumor growth from transient expansion of vestibular schwannomas following gamma knife radiosurgery. Acta Neurochir (Wien) 156:11211123. doi:10.1007/s00701-014-2063-3

18. Frisch CD, Jacob JT, Carlson ML, Foote RL, Driscoll CL, Neff BA, Pollock BE, Link MJ (2017) Stereotactic radiosurgery for cystic vestibular schwannomas. Neurosurgery 80:112-118. doi:10.1227/NEU.0000000000001376

19. Umekawa M, Hasegawa H, Shin M, Kawashima M, Nomura S, Nakatomi H, Saito N (2018) Radiosurgery induced anterior inferior cerebellar artery pseudoaneurysm treated with trapping and 
bypass. World Neurosurg 116:209-213. doi:10.1016/j.wneu.2018.04.161

20. Shin M, Ueki K, Kurita H, Kirino T (2002) Malignant transformation of a vestibular schwannoma after gamma knife radiosurgery. Lancet 360:309-310. doi:10.1016/S0140-6736(02)09521-1

21. Sughrue ME, Kaur R, Rutkowski MJ, Kane AJ, Yang I, Pitts LH, Parsa AT (2010) A critical evaluation of vestibular schwannoma surgery for patients younger than 40 years of age. Neurosurgery 67:1646-1653. doi:10.1227/NEU.0b013e3181f8d3d3 discussion 1653 - 1644.

22. Lobato-Polo J, Kondziolka D, Zorro O, Kano H, Flickinger JC, Lunsford LD (2009) Gamma knife radiosurgery in younger patients with vestibular schwannomas. Neurosurgery 65:294-300. doi:10.1227/01.NEU.0000345944.14065.35 discussion 300 - 291.

23. Breshears JD, Chang J, Molinaro AM, Sneed PK, McDermott MW, Tward A, Theodosopoulos PV (2019) Temporal dynamics of pseudoprogression after gamma knife radiosurgery for vestibular schwannomas-a retrospective volumetric study. Neurosurgery 84:123-131. doi:10.1093/neuros/nyy019

24. Li LF, Yu CP, Tsang AC, Taw BB, Lui WM (2020) Near-complete regression 19 years after gamma knife radiosurgery of vestibular schwannoma with massive pseudoprogression: case report. J Neurosurg May 8:1-4. doi:10.3171/2020.3.JNS20389

25. Park KY, Ahn JY, Lee JW, Chang JH, Huh SK (2009) De novo intracranial aneurysm formation after Gamma Knife radiosurgery for vestibular schwannoma. J Neurosurg 110:540-542. doi:10.3171/2008.9.JNS08860

26. Kim JH, Jung HH, Chang JH, Chang JW, Park YG, Chang WS (2017) Predictive factors of unfavorable events after gamma knife radiosurgery for vestibular schwannoma. World Neurosurg 107:175-184. doi:10.1016/j.wneu.2017.07.139

27. Yang I, Sughrue ME, Han SJ, Aranda D, Pitts LH, Cheung SW, Parsa AT (2010) A comprehensive analysis of hearing preservation after radiosurgery for vestibular schwannoma. J Neurosurg 112:851-859. doi:10.3171/2009.8.JNS0985

28. Prabhuraj AR, Yeole U, Arimappamagan A, Rao KVLN, Bhat DI, Dwarakanath S, Govindswamy B, Somanna S (2019) Effect of gamma knife radiosurgery on vestibular schwannoma with serviceable hearing: a single-center Indian study. World Neurosurg 127:e114-e123. doi:10.1016/j.wneu.2019.02.169

29. Roosli C, Linthicum FH, Cureoglu S, Merchant SN (2012) Dysfunction of the cochlea contributing to hearing loss in acoustic neuromas: an underappreciated entity. Otol Neurotol 33:473-480. doi:10.1097/MAO.0b013e318248ee02

30. Gouveris HT, Victor A, Mann WJ (2007) Cochlear origin of early hearing loss in vestibular schwannoma. Laryngoscope 117:680-683. doi:10.1097/MLG.0b013e31803146c5

31. Tamura M, Carron R, Yomo S, Arkha Y, Muraciolle X, Porcheron D, Thomassin JM, Roche PH, Régis J (2009) Hearing preservation after gamma knife radiosurgery for vestibular schwannomas presenting with high-level hearing. Neurosurgery 64:289-296. doi:10.1227/01.NEU.0000338256.87936.7C discussion 296. 
32. Johnson S, Kano H, Faramand A, Niranjan A, Flickinger JC, Lunsford LD (2019) Predicting hearing outcomes before primary radiosurgery for vestibular schwannomas. J Neurosurg:1-7. doi:10.3171/2019.5.JNS182765

33. Akamatsu Y, Sugawara T, Mikawa S, Saito A, Ono S, Takayama K, Jokura H, Seki H (2009) Ruptured pseudoaneurysm following gamma knife surgery for a vestibular schwannoma. J Neurosurg 110:543-546. doi:10.3171/2008.8.JNS08177

34. Matsumura H, Kato N, Hosoo H, Fujiwara Y (2015) Subarachnoid hemorrhage due to anterior inferior cerebellar artery aneurysms associated with gamma knife surgery for vestibular schwannomas. Acta Neurochir (Wien) 157:1765-1767. doi:10.1007/s00701-015-2552-z discussion 1767.

35. Murakami M, Kawarabuki K, Inoue Y, Ohta T (2016) Ruptured pseudoaneurysm after gamma knife surgery for vestibular schwannoma. Neurol Med Chir (Tokyo) 56:38-42. doi:10.2176/nmc.cr.20150034

36. Takao T, Fukuda M, Kawaguchi T, Nishino K, Ito Y, Tanaka R, Sato M (2006) Ruptured intracranial aneurysm following gamma knife surgery for acoustic neuroma. Acta Neurochir (Wien) 148:13171318. doi:10.1007/s00701-006-0912-4 discussion 1318.

37. Sunderland G, Hassan F, Bhatnagar P, Mitchell P, Jayakrishnan V, Forster D, Mendelow AD (2014) Development of anterior inferior cerebellar artery pseudoaneurysm after gamma knife surgery for vestibular schwannoma. A case report and review of the literature. Br J Neurosurg 28:536-538. doi:10.3109/02688697.2013.847168

38. Mascitelli JR, McNeill IT, Mocco J, Berenstein A, DeMattia J, Fifi JT (2015) Ruptured distal AICA pseudoaneurysm presenting years after vestibular schwannoma resection and radiation. BMJ Case Rep 2015 doi:10.1136/bcr-2015-011736

39. Cahan WG, Woodard HQ, Higinbotham NL, Stewart FW, Coley BL (1948) Sarcoma arising in irradiated bone; report of 11 cases. Cancer 1:3-29

40. Akamatsu Y, Murakami K, Watanabe M, Jokura H, Tominaga T (2010) Malignant peripheral nerve sheath tumor arising from benign vestibular schwannoma treated by gamma knife radiosurgery after two previous surgeries: a case report with surgical and pathological observations. World Neurosurg 73:751-754. doi:10.1016/j.wneu.2010.04.009

41. Yang T, Rockhill J, Born DE, Sekhar LN (2010) A case of high-grade undifferentiated sarcoma after surgical resection and stereotactic radiosurgery of a vestibular schwannoma. Skull Base 20:179183. doi:10.1055/s-0029-1242195

42. Demetriades AK, Saunders N, Rose P, Fisher C, Rowe J, Tranter R, Hardwidge C (2010) Malignant transformation of acoustic neuroma/vestibular schwannoma 10 years after gamma knife stereotactic radiosurgery. Skull Base 20:381-387. doi:10.1055/s-0030-1253576

43. Peker HO, Gok H, Altay T (2019) Malignant transformation of vestibular schwannoma after stereotactic radiosurgery. World Neurosurg January 10. doi:10.1016/j.wneu.2018.12.149

44. Yanamadala V, Williamson RW, Fusco DJ, Eschbacher J, Weisskopf P, Porter RW (2013) Malignant transformation of a vestibular schwannoma after gamma knife radiosurgery. World Neurosurg 
79:593;e591-598. doi:10.1016/j.wneu.2012.03.016

45. Wilkinson JS, Reid H, Armstrong GR (2004) Malignant transformation of a recurrent vestibular schwannoma. J Clin Pathol 57:109-110. doi:10.1136/jcp.57.1.109

46. Thomsen J, Mirz F, Wetke R, Astrup J, Bojsen-Møller M, Nielsen E (2000) Intracranial sarcoma in a patient with neurofibromatosis type 2 treated with gamma knife radiosurgery for vestibular schwannoma. Am J Otol 21:364-370. doi:10.1016/s0196-0709(00)80046-0

47. Seferis C, Torrens M, Paraskevopoulou C, Psichidis G (2014) Malignant transformation in vestibular schwannoma: report of a single case, literature search, and debate. J Neurosurg 121 Suppl:160-166. doi:10.3171/2014.7.GKS141311

48. Chen H, Zhang X, Zhang Z, Yang T, Wang Z, Wu H (2014) The role of NF2 gene mutations and pathogenesis-related proteins in sporadic vestibular schwannomas in young individuals. Mol Cell Biochem 392:145-152. doi:10.1007/s11010-014-2011-9

\section{Figures}
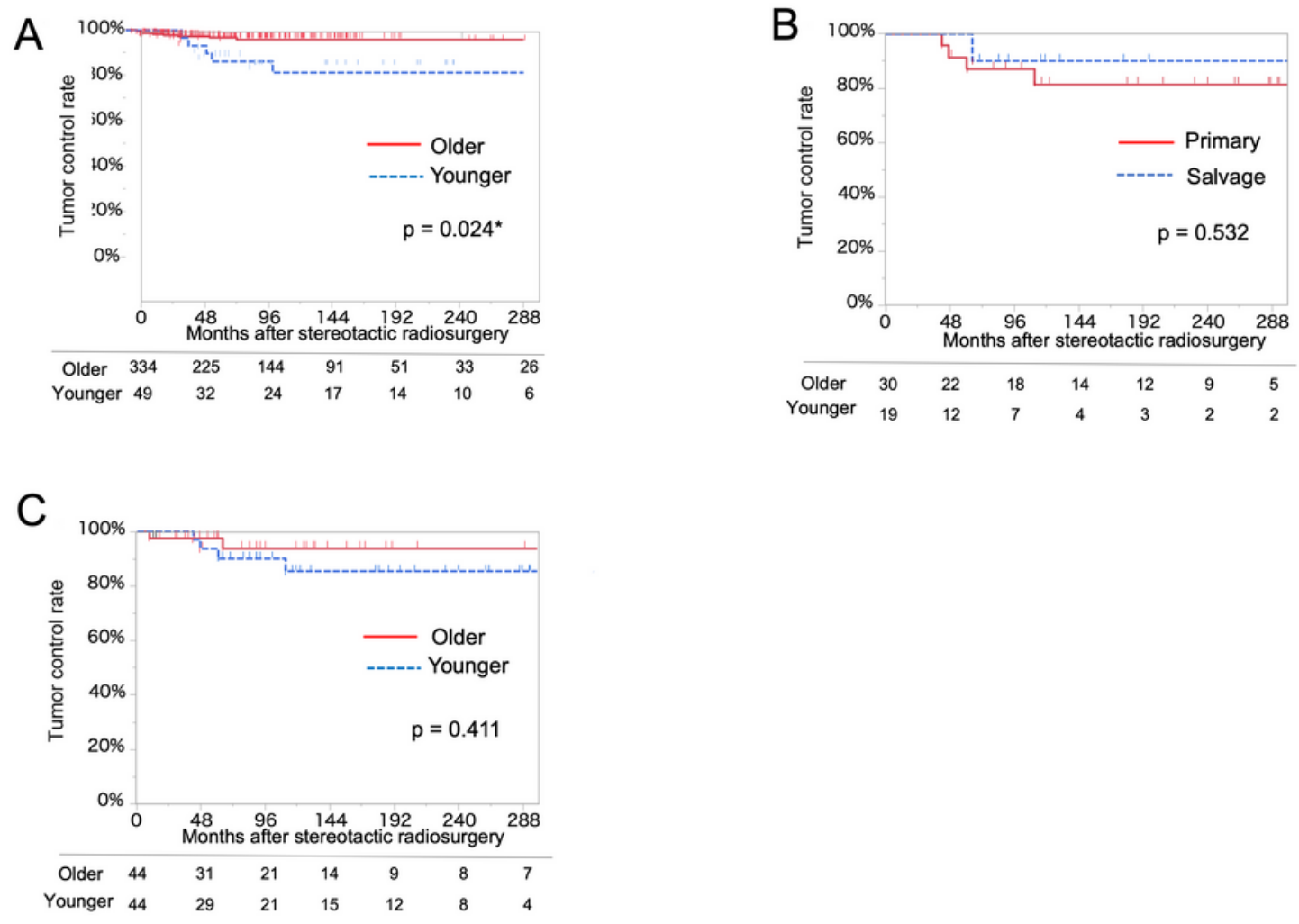

\section{Figure 1}

a: Cumulative tumor control rates estimated using the Kaplan-Meier method before propensity score matching (red line: older cohort; blue line: younger cohort); b: tumor control rates between primary SRS and salvage SRS after resection in the younger cohort (red line: primary SRS; blue line: salvage SRS after 
resection); c: tumor control rates after propensity score matching (red line: older cohort; blue line: younger cohort)

\section{Supplementary Files}

This is a list of supplementary files associated with this preprint. Click to download.

- Dataset.xlsx 